\title{
Desenvolvimento da nova Biblioteca Digital da Biblioteca Brasiliana USP: Relato de Experiência
}

\section{Desarrollo de la nueva Biblioteca Digital de la Biblioteca Brasiliana USP: Relato de Experiencia}

\section{Development of the new Digital Library of the Brasiliana Library USP: Experience Report}

\author{
Rodrigo Moreira Garcia'
}

\author{
Palavras-chave: \\ Bibliotecas Digitais \\ Digitalização de Acervos \\ Acesso aberto \\ Coordenação de Projetos \\ Projetos Sustentáveis
}

Resumo:

A Biblioteca Brasiliana Guita e José Mindlin é um órgão da Pró-Reitoria de Cultura e Extensão Universitária. Como entidade acadêmica da Universidade de São Paulo, configura-se como um centro interdisciplinar de informação e documentação, pesquisa e difusão científica. Tendo como finalidade a preservar e proporcionar irrestrito acesso de seu acervo, a estratégia adotada foi o desenvolvimento de uma biblioteca digital brasiliana. Este trabalho apresenta um relato de experiência do desenvolvimento da nova plataforma para a Biblioteca Digital da BBM. Apresenta uma retrospectiva desde o projeto-piloto, os problemas e êxitos no decorrer do percurso do projeto. Relata os desafios enfrentados e as soluções encontradas para a retomada dos processos de digitalização e desenvolvimento da coleção digital. Por fim, apresenta os próximos passos, desafios e aponta para a necessidade de definições estratégicas para a sua sustentabilidade institucional. 


\section{Resumen:}

La Biblioteca Brasiliana Guita y José Mindlin es un órgano de la Pro-Rectoría de Cultura y Extensión Universitaria. Como entidad académica de la Universidad de São Paulo, se configura como un centro interdisciplinario de información y documentación, investigación y difusión científica. Con la finalidad de preservar y proporcionar irrestricto acceso de su acervo, la estrategia adoptada fue el desarrollo de una biblioteca digital brasiliana. Este trabajo presenta un relato de experiencia del desarrollo de la nueva plataforma para la Biblioteca Digital de BBM. Presenta una retrospectiva desde el proyecto piloto, los problemas y éxitos en el transcurso del recorrido del proyecto. Relata los desafíos enfrentados y las soluciones encontradas para la reanudación de los procesos de digitalización y desarrollo de la colección digital. Por último, presenta los próximos pasos, desafíos y apunta a la necesidad de definiciones estratégicas para su sostenibilidad institucional.
Palabras clave:

Bibliotecas Digitales

Digitalización de Acervos

Acceso abierto

Coordinación de Proyectos

Proyectos Sostenibles

\section{Keywords:}

Digital Libraries

Digitalization

of Collections

Open Access

Project coordination

Sustainable Projects

\section{Abstract:}

The Brasiliana Guita and José Mindlin Library is an organ of the ProRectory of Culture and University Extension. As an academic entity of the University of São Paulo, it is an interdisciplinary center for information and documentation, research and scientific dissemination. With the purpose of preserving and providing unrestricted access to its collection, the strategy adopted was the development of a Brazilian digital library. This paper presents an experience report on the development of the new platform for the Digital Library of BBM. It presents a retrospective from the pilot project, the problems and successes throughout the course of the project. It reports the challenges faced and the solutions found for the resumption of the processes of digitalization and development of the digital collection. Finally, it presents the next steps, challenges and points to the need for strategic definitions for its institutional sustainability. 


\section{Desenvolvimento da nova Biblioteca Digital da Biblioteca Brasiliana USP: Relato de Experiência}

\section{Introdução}

Inaugurada em março de 2013, a Biblioteca Brasiliana Guita e José Mindlin (BBM) é um órgão e entidade acadêmica da Pró-Reitoria de Cultura e Extensão Universitária (PRCEU) da USP. O projeto Brasiliana USP iniciou-se em 2005 e foi pensado para abrigar e integrar a coleção Brasiliana, doada por José Mindlin à USP, e o Instituto de Estudos Brasileiros (IEB), de modo a configurar a BBM como um centro interdisciplinar de informação e documentação. A iniciativa surgiu da ideia de se "[...] criar instrumentos que envolvessem o diálogo entre diversas unidades da USP" (JANCSÓ, 2010, p. 315).

Em 2009, como parte do projeto Brasiliana USP, é colocada on-line a primeira versão da Biblioteca Brasiliana Digital da BBM. Iniciado em 2008 o projeto-piloto Biblioteca Brasiliana Digital", visava investigar um modelo de implantação de biblioteca digital, atendendo aos princípios de preservação de acervos bibliográficos e de democratização do acesso, assim como, de suporte à pesquisa, de forma a estabelecer a BBM como centro de reflexão, produção e difusão de estudos e da cultura brasileira.

\section{O Projeto Corisco}

A plataforma Corisco, foi desenvolvida a partir da ideia de tornar disponível on-line o acervo da BBM. A visão do projeto-piloto era além de desenvolver uma plataforma de software para a biblioteca digital,

[...] tornar a plataforma de software reutilizável para outras iniciativas de bibliotecas digitais que não disponham de recursos ou que não tenham interesse em alocar recursos preciosos em desenvolvimento complexo de sistemas de software (ALENCAR et al, 2012, p.1).

Basicamente o desenvolvimento se deu com a customização de um sistema base para o repositório digital. Optou-se pelo DSpace III, software open source, como repositório, com outros componentes auxiliares como Djatokalv (servidor de imagens) e os visualizadores IIPImage ${ }^{\vee}$ e BookReader $^{\mathrm{VI}}$ (este último implantado integralmente).

Além da plataforma, foram adquiridos para o projeto-piloto máquinas robotizadas para a digitalização dos livros, softwares para o tratamento, edição e compactação das imagens, reconhecimento ótico de caracteres (OCR ${ }^{\mathrm{VII}}$ ) e geração de versões em PDF, além de servidores para a instalação das aplicações e armazenamento das imagens.

Como padrão de metadados, foi adotado o esquema Dublin Core ${ }^{\text {VIII }}$, amplamente adotado para a descrição de diversas tipologias documentais em ambiente Web.

Foi montada uma equipe entre 15 bolsistas, além de profissionais contratados, professores, pesquisadores e técnicos, para todo o desenvolvimento, manutenção e geração de conteúdo para a Biblioteca Digital.

\section{Problemas e êxitos}

Talvez dado o pioneirismo (a Biblioteca Brasiliana Digital da BBM surgiu há exatos 10 anos, antes mesmo da construção do complexo Brasiliana) e a inexperiência, muitas das tomadas de decisões, que foram feitas à época, não seriam adotadas hoje. Ao longo dos últimos anos e com a maturidade de procedimentos e aprimoramento das Tecnologias de Informação e Comunicação, atualmente já existe uma base mais estabelecida de como iniciar, 
planejar e executar projetos de digitalização de diversos tipos de materiais.

A começar pelo desenvolvimento da Plataforma, muitas customizações foram realizadas diretamente no código do programa, tornando difícil, ou até mesmo, impossibilitando a atualização da plataforma DSpace para novas versões. Isto fragilizou o bom funcionamento da biblioteca digital, acarretando, sobretudo, em inconsistências quanto a visualização do objeto digital, lentidão do sistema, dentre outros problemas que a plataforma veio apresentando ao longo do tempo.

Tratando-se de um projeto-piloto acadêmico de pesquisa, a rotatividade das equipes (em sua maioria bolsistas e estagiários) envolvidas era constante, além do projeto contar com vários profissionais terceirizados contratados por tempo determinado. Isto, embora tenha contribuído para a formação de vários futuros profissionais e contribuído para a formação continuada de profissionais de diversas áreas, ao final destes financiamentos pontuais, característicos de projetos acadêmicos de pesquisa, a evasão de recursos humanos impactou a continuidade do desenvolvimento da biblioteca digital. Soma-se a isto a falta de um coordenador técnico/operacional|X que pudesse gerenciar o desenvolvimento do projeto, realizando a coordenação de equipes e tarefas, workflow (conservação, digitalização, descrição bibliográfica etc.), fazer a gestão do conhecimento, elaborar documentação técnica, etc.

A aquisição de máquinas de digitalização "robotizadas", embora tenha tido um grande apelo de inovação e modernidade, constatou-se que para o material a ser digitalizado (obras raras, que necessitam de diversos cuidados de preservação e conservação), não eram as mais adequadas. Os modelos adquiridos eram apropriados para projetos de digitalização em grande escala (em massa) e para tipos de materiais que não necessitam de cuidados especiais (como teses e dissertações, relatórios, entre outros tipos documentais encadernados), pois seus sistemas automatizados de hastes, presilhas e sistema de sucção, além de provocar interferências nas imagens (veja exemplos logo abaixo), poderiam danificar as páginas das obras.

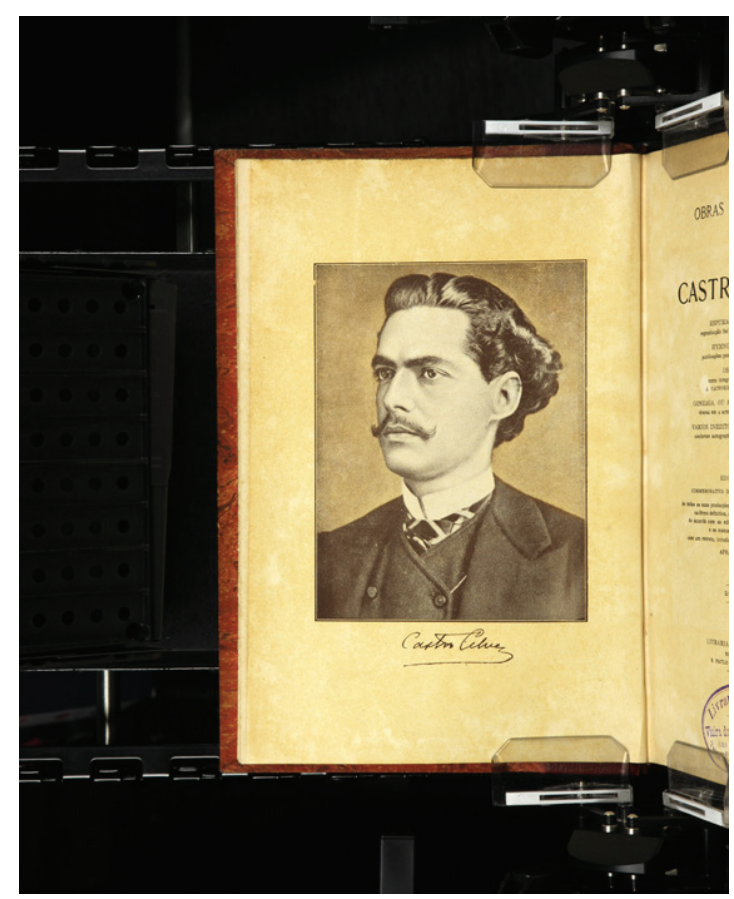

Figura 1 - Exemplo de interferência: Presilhas plásticas sobre as páginas Fonte: BBM 


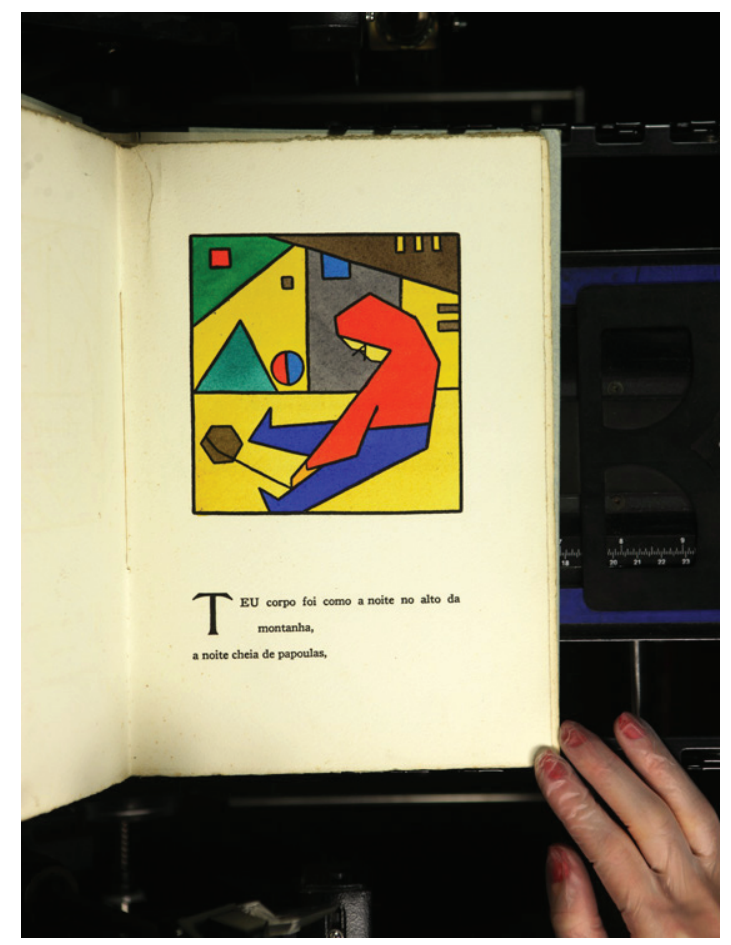

Figura 2 - Exemplo de interferência: Mão do operador sobre a página (devido à necessidade de segurá-la para a captura da imagem)

Fonte: BBM

Também, as primeiras digitalizações são próximas do aspecto de uma fo- tocópia, com grande perda de dados e das características do objeto original:

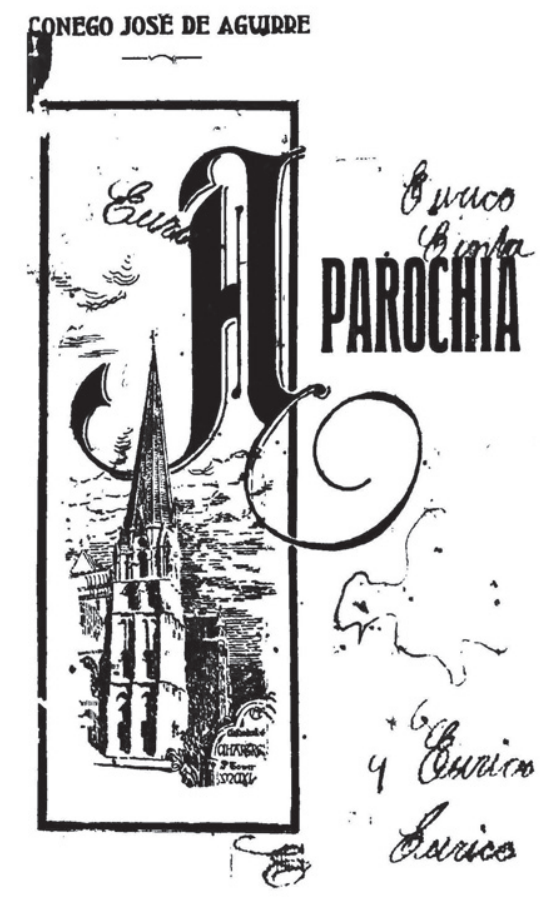

Figura 3 - Exemplo de tratamento de imagem anteriormente realizado, com perda de dados e das características originais. Fonte: BBM 


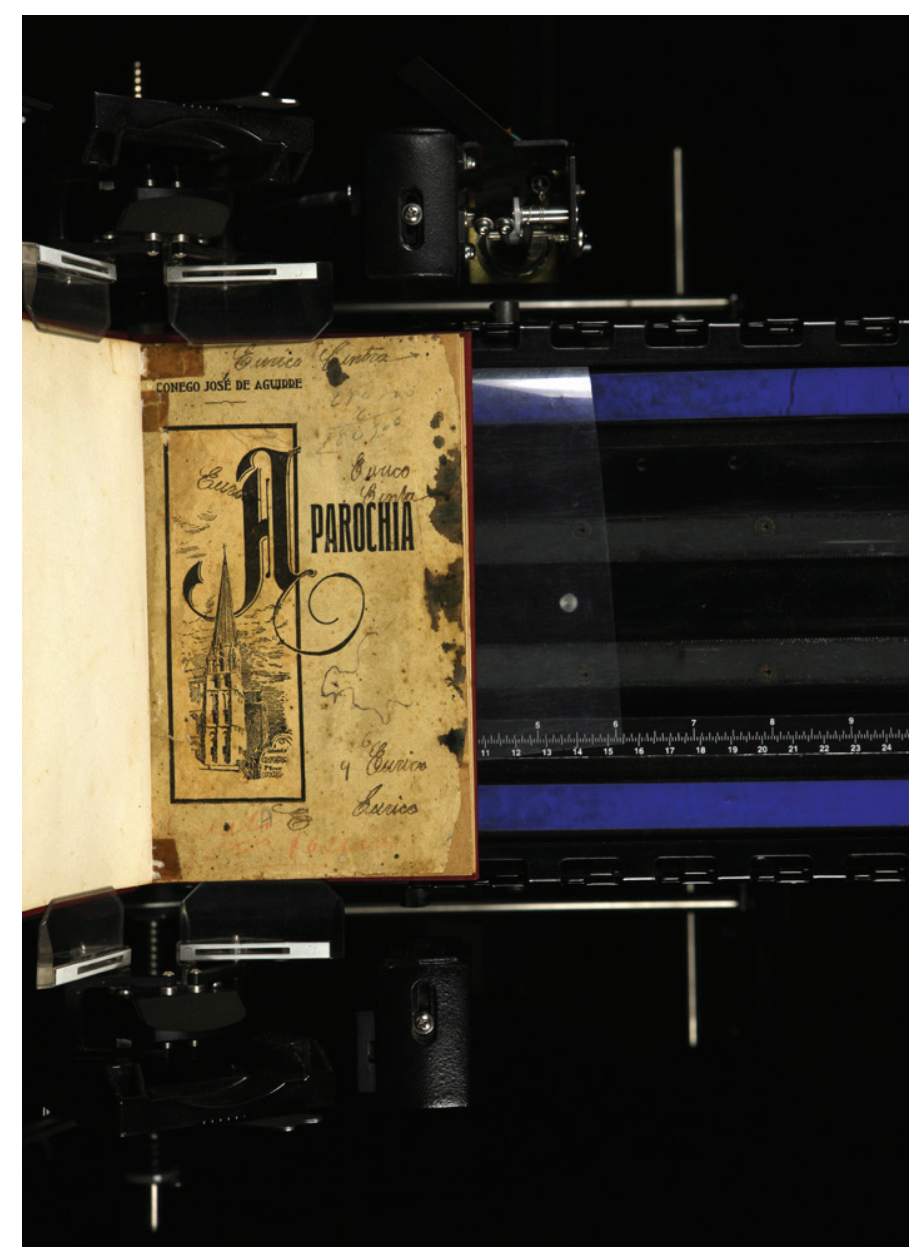

Figura 4 - Crop da imagem anterior, apresentando as características originais da página (imagem não tratada).

Fonte: BBM

Embora, durante o desenvolvimento do projeto-piloto, muitos problemas de nível técnico e operacional tenham se apresentado, a iniciativa de uma Biblioteca Brasiliana Digital sempre esteve em consonância com os movimentos nacionais e internacionais de Acesso Aberto (Open Access) aos conteúdos digitais. Exemplo disso são os seis princípios da Biblioteca Brasiliana Digital definidos com o objetivo de apoiar o "Memorando de Intenções sobre conteúdos digitais" (CGI.BR, 2007), que se tratava de um esforço para a definição de diretrizes para uma política pública de apoio à produção de conteúdos digitais:

1. Uma biblioteca digital como instrumento de uma política nacional de produção de conteúdos para a rede mundial de computadores, contribuindo para a redefinição positiva da presença da língua portuguesa e da cultura nacional.

2. Uma biblioteca digital para a difusão de uma coleção original: uso das novas tecnologias como forma de conciliação das necessidades de preservação do acervo e o imperativo de universalizar o acesso. Rejeição de um modelo custodial de biblioteca.

3. Orientação para o contexto-usuário: a formação do acervo digital deve estar orientada por uma política de acesso universal; o usuário (e pensamos em termos polissêmicos) tem centralidade na construção deste acervo digital. 
4. Uma biblioteca digital como instrumento da educação nacional: compromisso com a produção de materiais didáticos, com a formação de quadros em todos os níveis, desde o ensino fundamental até a pesquisa avançada.

5. Uma biblioteca digital pública: difusão do acervo, acesso universal (preservados os direitos do autor) e democratização da cultura. Adesão à Declaração de Berlim sobre o Acesso Livre ao Conhecimento nas Ciências e Humanidades ${ }^{x}$ (Berlin Declaration on Open Access to Knowledge in the Sciences and Humanities), de 2003: "acesso livre significa a livre disponibilização na Internet de literatura de caráter científico, permitindo a qualquer utilizador pesquisar, consultar, descarregar, imprimir, copiar e distribuir, o texto integral de artigos e outras fontes de informação científica". Adesão aos protocolos da Iniciativa Open Archives ${ }^{X I}$ (OAI-PMH - Open Archives Initiative Protocol for Metadata Harvesting) - protocolo desenvolvido para permitir que os metadados sejam acessíveis por diversos serviços de busca e compartilhados pelos repositórios digitais.

6. Compromisso com a democratização de nossa experiência. Adesão aos princípios do software livre (open source) (BRASILIANA USP, 2009).

O engajamento e o envolvimento da BBM em iniciativas e movimentos "open", enquanto instituição, têm sido relativamente bastante tímida, sobretudo pelas mudanças de foco (ou de incompreensão) realizadas pelos corpos diretivos que se sucederam.

No limiar da possibilidade de novas contratações de efetivo, que dariam continuidade a todo um trabalho para o estabelecimento e crescimento do projeto, as circunstâncias foram desfavoráveis e,
Nesta conjuntura complexa, na qual se articulam crises econômica e política, as IES se encontram afetadas, primeiramente, pela recessão e pelos cortes sistemáticos advindos da federação e de diversos entes federativos (MANCEBO, 2017, p. 884).

Tal conjuntura, além de impactar com as interrupções de contratações de novos efetivos, culminou ainda em dois programas de incentivo à demissão voluntária (PIDV's em 2015 e 2016), que abalaram estruturalmente qualquer desenvolvimento em andamento. A drástica redução orçamentária e de efetivo, entre outros fatores, impactou, inclusive, a continuidade de planejamento, a gestão e a permanência e estabilidade de um corpo diretivo coerente.

\section{Freio de ArrumaçãoXII}

Em 2015 a BBM contava com um corpo de efetivos de pouco mais de uma dezena de profissionais técnicos (entre os níveis superior, em sua maioria, técnico e básico), para atender a todas as áreas (administrativo, operacional, manutenção, segurança etc.). Contando com a mobilidade ${ }^{\text {XIII }}$ inter-unidades da Universidade, houve um rearranjo da equipe envolvida diretamente no workflow de digitalização e desenvolvimento da biblioteca digital.

Naquele momento, as atividades de submissão de novos itens para a biblioteca digital estavam interrompidas haviam dois anos aproximadamente e era necessário urgentemente a retomada das atividades.

Neste ínterim, um especialista em laboratório, que ocupa o Laboratório de Digitalização, desenvolveu um sistema para a gestão das atividades de digitalização: 


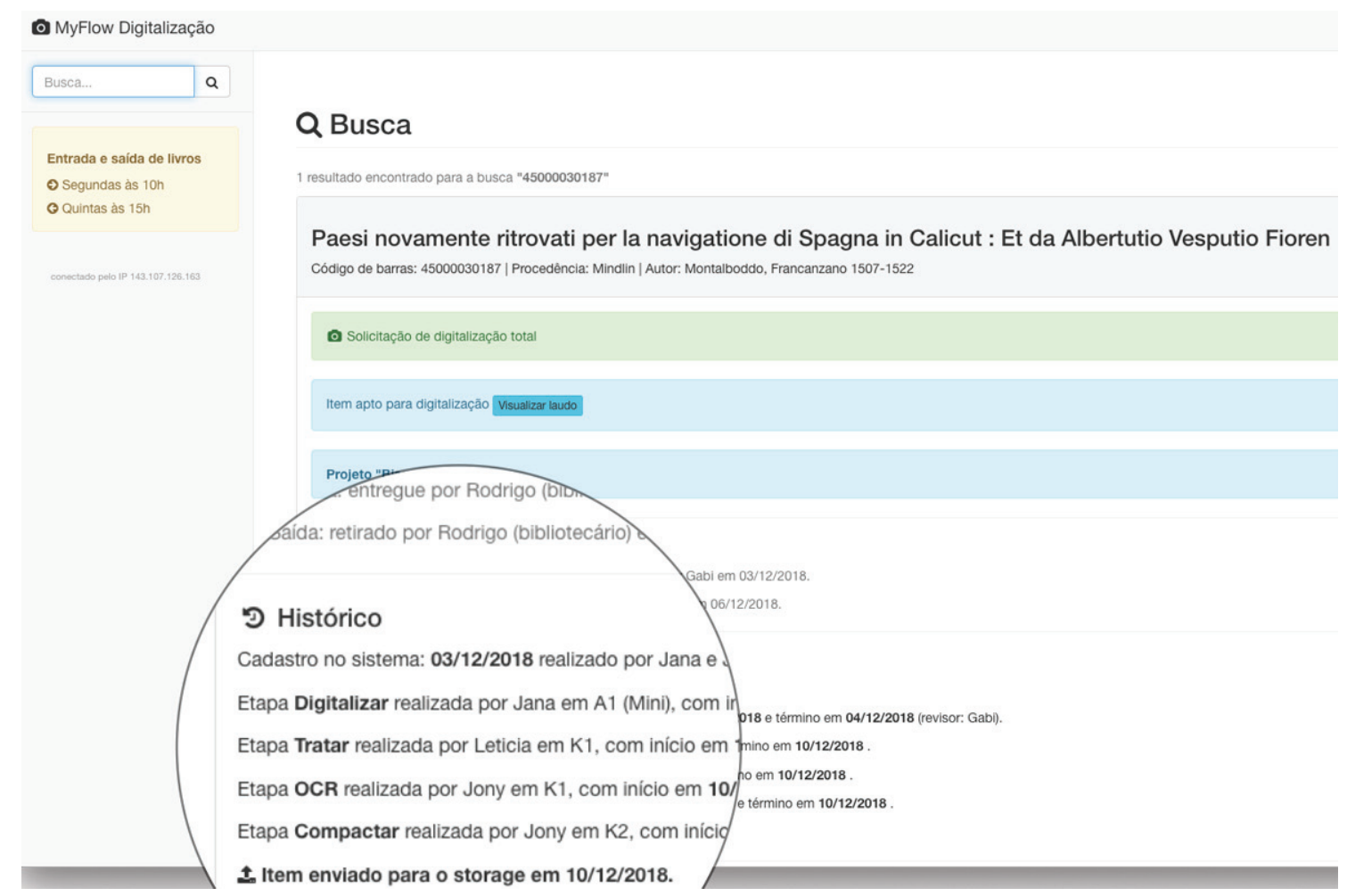

Figura 5 - Sistema "MyFlow" para o gerenciamento das atividades de Digitalização.

Fonte: BBM

Ainda foi possível adquirir novas máquinas para digitalização, mais modernas e adequadas (e por um custo inferior às anteriormente adquiridas) para o material bibliográfico que a biblioteca possui. São operadas manualmente, possuem base em formato $\mathrm{V}$, para evitar danos à lombada do livro, e acessório em vidro para evitar as curvaturas das páginas, além de câmeras digitais de maior qualidade e precisão.

Uma readequação dos processos de captura digital foi realizada, pois segundo a IFLA (2015, p. 14):

Nos processos de digitalização de materiais raros e únicos é importante conservar e recriar, tanto quanto possível, o aspecto material do objeto original. Assim, a captura deve ser do objeto físico inteiro e não apenas de seu conteúdo intelectual. Por isso, é necessário fotografar páginas completas frente e verso (incluindo as margens) e ter o cuidado de não cortar imagens que possam se encontrar nas margens. Os volumes encadernados devem ser digitalizados capa a capa, incluindo as folhas de guarda, as folhas em branco e as encadernações [...].

Assim, para manter um padrão mínimo de qualidade, o laboratório de digitalização reuniu os procedimentos utilizados para a geração de objetos digitais em um conjunto de manuais técnicos, mais especificamente relacionados às três etapas iniciais do processo (triagem, digitalização e tratamento digital), em razão da grande quantidade de procedimentos existentes em cada uma das etapas executadas. Tais manuais são a base do treinamento das equipes (de bolsistas e estagiários) e servem como referência contínua para os procedimentos adotados pelo laboratório.

Com a vinda de um bibliotecário, com experiência no desenvolvimento e gestão de bibliotecas digitais, deu-se início a uma série de reestruturações, de for- 
ma a estandardizar e otimizar o workflow das atividades.

Para tornar o workflow de digitalização (que envolve desde a seleção do material pela equipe curadora ou por solicitação de usuário; a triagem/avaliação, higienização e pequenos reparos pelo laboratório de conservação; a triagem/avaliação pelo laboratório de digitalização e suas etapas; até a submissão do item na plataforma digital) mais fluido e funcional, era necessário que se adotasse um único identificador para as obras, ou seja, o mesmo identificador para a obra física e digital, pois era quase impossível (despendia-se muito tempo para se saber) identificar se determinada obra já havia sido digitalizada ou não (já armazenada no servidor - Storage). Também sem um controle eficaz, muitas vezes uma obra já digitalizada era encaminhada para digitalização, e só se ficava sabendo quando o item chegava ao laboratório de digitalização. Assim, foi estabelecido que o barcode já adotado no sistema ALEPH/DEDALUS (sistema de administração de bibliotecas utilizado para a gestão do Catálogo Bibliográfico da USP ${ }^{X I V}$ ) seria o identificador da obra fosse sua versão física (Catálogo USP) fosse a versão digital (Storage e DSpace). Para isso, tudo aquilo já armazenado no Storage, deveria receber o barcode (algo em torno de 2580 itens). Uma força tarefa foi montada para realizar esta atividade de "tombamento" dos itens digitais.

Também não se tinha um controle claro de quantas obras haviam sido encaminhadas aos laboratórios e exposições (este controle era feito por meio de planilhas que nem sempre estavam atualizadas). Um grande problema, mas, facilmente resolvido com a adoção do módulo de circulação do sistema ALEPH/DEDALUS. Foi configurado a opção de circulação interna de itens. Desde então, somente itens que já receberam o barcode (obras tombadas), podem ser encaminhadas aos laboratórios ou para as exposições.

Mais um exemplo foi a utilização de um sistemas de cores simples (verde: digitalizado; amarelo: parcialmente digitalizado; vermelho: não digitalizado; e dourado para indicar obra rara ou especial) para a identificação de forma visual nas estantes o status da digitalização de determinado item:

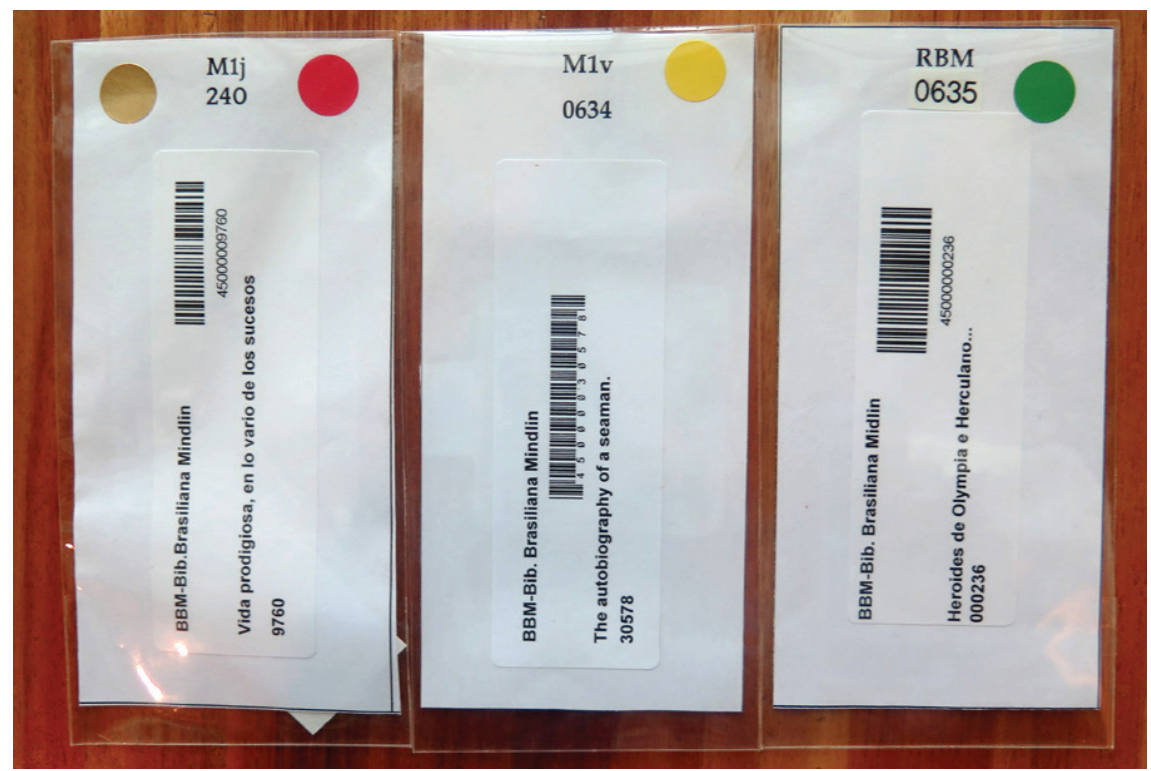

Figura 6 - Sistemas de cores nas papeletas de localização, que indicam status da digitalização do item. Fonte: BBM 
A conscientização da equipe envolvida para a importância destes controles também foi trabalhada e o estabelecimento de regras e medidas relativamente simples, fizeram grande diferença na otimização do workflow. Um conjunto de manuais para os procedimentos técnicos que envolvem o fluxo de digitalização também foi elaborado para documentar e auxiliar no treinamento da equipe.

Mas ainda era preciso que a plataforma digital voltasse a receber novas obras. Para isso, algumas estratégias foram tomadas.

\section{Sustentabilidade}

Sabendo da falta de um analista de sistemas ${ }^{\mathrm{XV}}$ com o perfil de programador/desenvolvedor, buscou-se dentro da própria universidade o know-how necessário para o desenvolvimento de uma nova plataforma para a biblioteca digital, já que a anterior não tinha mais condições de manutenção. Assim, foi solicitado à Direção (à época) que estabelecesse contato com a Superintendência de Tecnologia da Informação (STI) XVI para que a equipe técnica de ambos órgãos pudesse trabalhar no desenvolvimento de uma nova plataforma. Assim, em juIho de 2015 foi formalizado a cooperação técnica entre a BBM e a STI, mais especificamente com o Centro de Tecnologia da Informação de São Carlos (CeTI-SC ${ }^{\mathrm{XVII}}$, pioneiro no desenvolvimento de umas das primeiras bibliotecas de teses e dissertações ${ }^{\mathrm{XVIII}}$ em âmbito nacional. A equipe BBM/CeTI-SC, então, realizou um diagnóstico de toda a situação do projeto atual (estrutura de hardwares e softwares; arquitetura de dados e de informação; problemas identificados e possíveis soluções; além de estabelecer um cronograma de atividades, com as responsabilidades de cada órgão.
Coube então à BBM, na figura do bibliotecário que assumiu a coordenação técnica do novo desenvolvimento, gerenciar a migração dos dados da antiga para a nova plataforma; revisar os metadados, corrigir sistema de arquivos no servidor (Storage), demandar desenvolvimentos (novo DSpace; módulo importação; visualizador; customizações de layout; entre outros), administrar a nova plataforma digital e seus registros bibliográficos.

A BBM já havia, no ano de 2012 , sido incorporada ao Sistema Integrado de Bibliotecas da USP (SIBi/USP ${ }^{\mathrm{XIX}}$ ) e em 2013 parte do antigo catálogo em Winisis $^{x x}$ da Biblioteca Mindlin, foi migrado para o Sistema ALEPH/DEDALUS. Como o antigo catálogo nunca foi trabalhado por profissionais bibliotecários, o fato é que os dados não estão de acordo com as normas, códigos e padrões de catalogação interna-

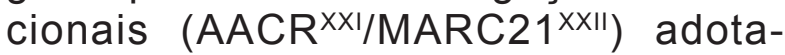
dos pelo SIBI/USP. Nas atividades de relocalização (rearranjo das obras nas estantes) e tombamento (atribuição de barcode), a equipe de tratamento técnico da informação está fazendo a revisão e correção dos registros bibliográficos, dentro das normas e padrões adotados.

Então, o tratamento técnico das obras do acervo da BBM já é feito no módulo de catalogação/indexação do sistema ALEPH/DEDALUS. Logo, o natural seria reaproveitar estes registros (já corrigidos) para a Biblioteca Digital. Assim, foi demandado ao SIBi/USP, que disponibilizasse um SET-BBM, para que, via protocolo OAl-PMH, fosse possível a importação daqueles registros necessários para a nova Biblioteca Digital. E para gerenciar esta importação, O CeTI-SC/STI desenvolveu um aplicativo para a importação de novos registros, que também faz a conversão do Formato 
MARC21 para Dublin Core. Para isso, também foi revisado o conjunto de metadados necessários para a importação na biblioteca digital.

Foi instalada a versão 5.5 do DSpace. Foi estratégico manter o DSpace como plataforma de desenvolvimento da Biblioteca Digital da BBM, pois além de facilitar a migração dos metadados da antiga versão para a nova, o DSpace é um software open source atualmente mantido por uma ampla comunidade de desenvolvedores liderada pela iniciativa sem fins lucrativos DuraSpace ${ }^{\mathrm{XXII}} e$, por isso, é uma das ferramentas mais utilizadas por instituições acadêmicas e de pesquisa para a criação de repositórios institucionais e bibliotecas digitais de acesso aberto, segundo o Diretório Global de Repositórios Open Access OpenDOAR ${ }^{\mathrm{XIV}}$ :

\section{Software Platforms Overview}
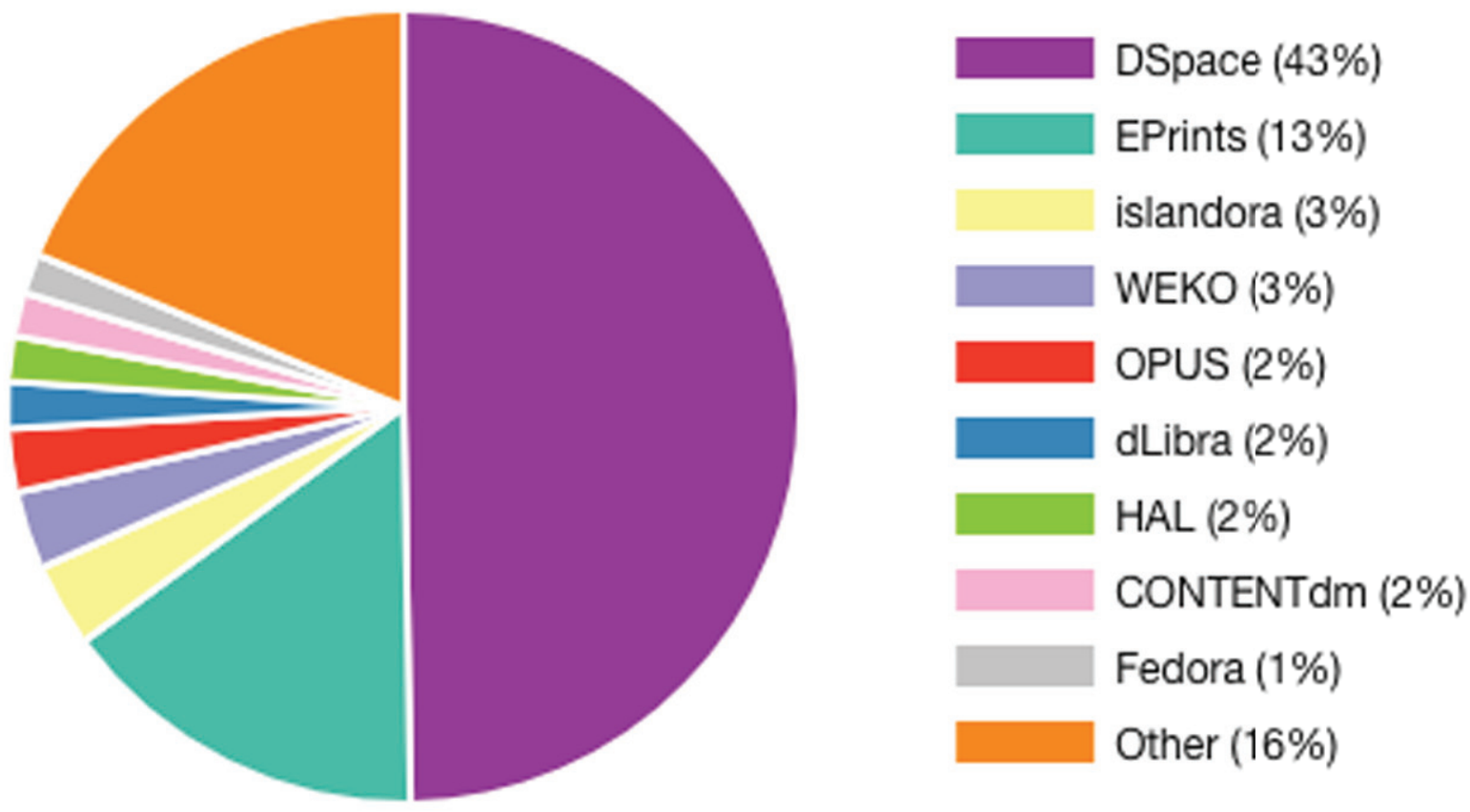

Figura 7 - Visão geral de plataformas de software open source.

Fonte: http://v2.sherpa.ac.uk/view/repository_visualisations/1.html. Acesso em: 18 dez. 2018

Aideia foi manter a plataforma com o menor número de customizações possíveis a fim de permitir sua atualização. Dentre algumas das customizações realizadas foi a possibilidade de escolher a imagem para destacar a obra (antes, por default, era a primeira imagem, normalmente a capa da encadernação, sem qualquer informação): 


\section{Biblioteca Brasiliana ejosé Mindlin Â Página inicial do Acervo Digital}

Buscar no acervo digital Q Idioma -
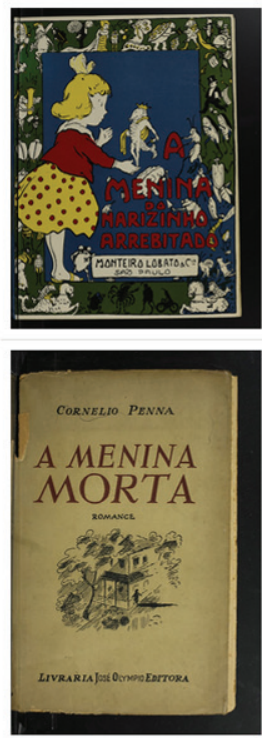

A menina morta, romance

Penna, Cornélio,

1896-1958; Jardim,

Luis, il

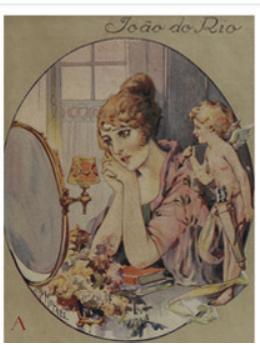

A mulher e os espelhos

Rio, Joâo do,

1881-1921

Figura 8 - Exemplo de imagens em destaque.

Fonte: BBM

Outra modificação foi a forma de visualizar as obras. Antes, abria-se um Viewer na própria página. Agora ao clicar em Visualizar/View o usuário é levado a outra página/aba do navegador, com uma visão mais ampla da obra:

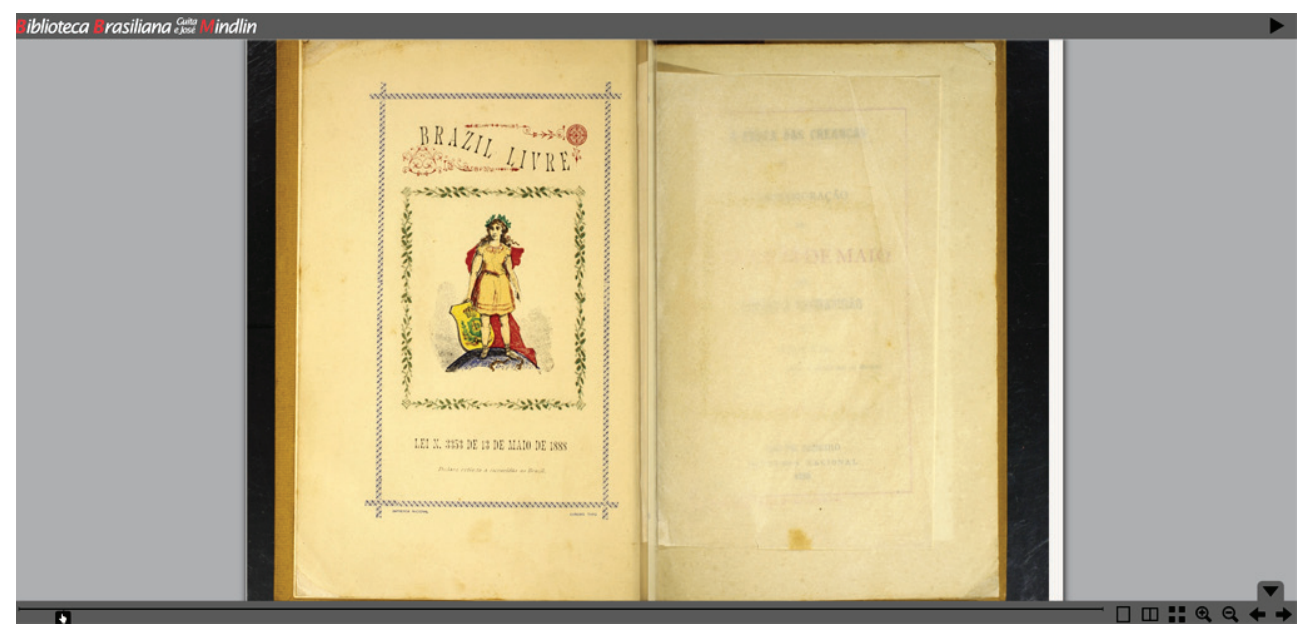

Figura 9 - Exemplo de Obra vista pelo visualizador. Fonte: BBM 
Caso seja uma obra em volumes ou fascículos, um pop-up é apresentado, para que o usuário escolha aquele que desejar ver:

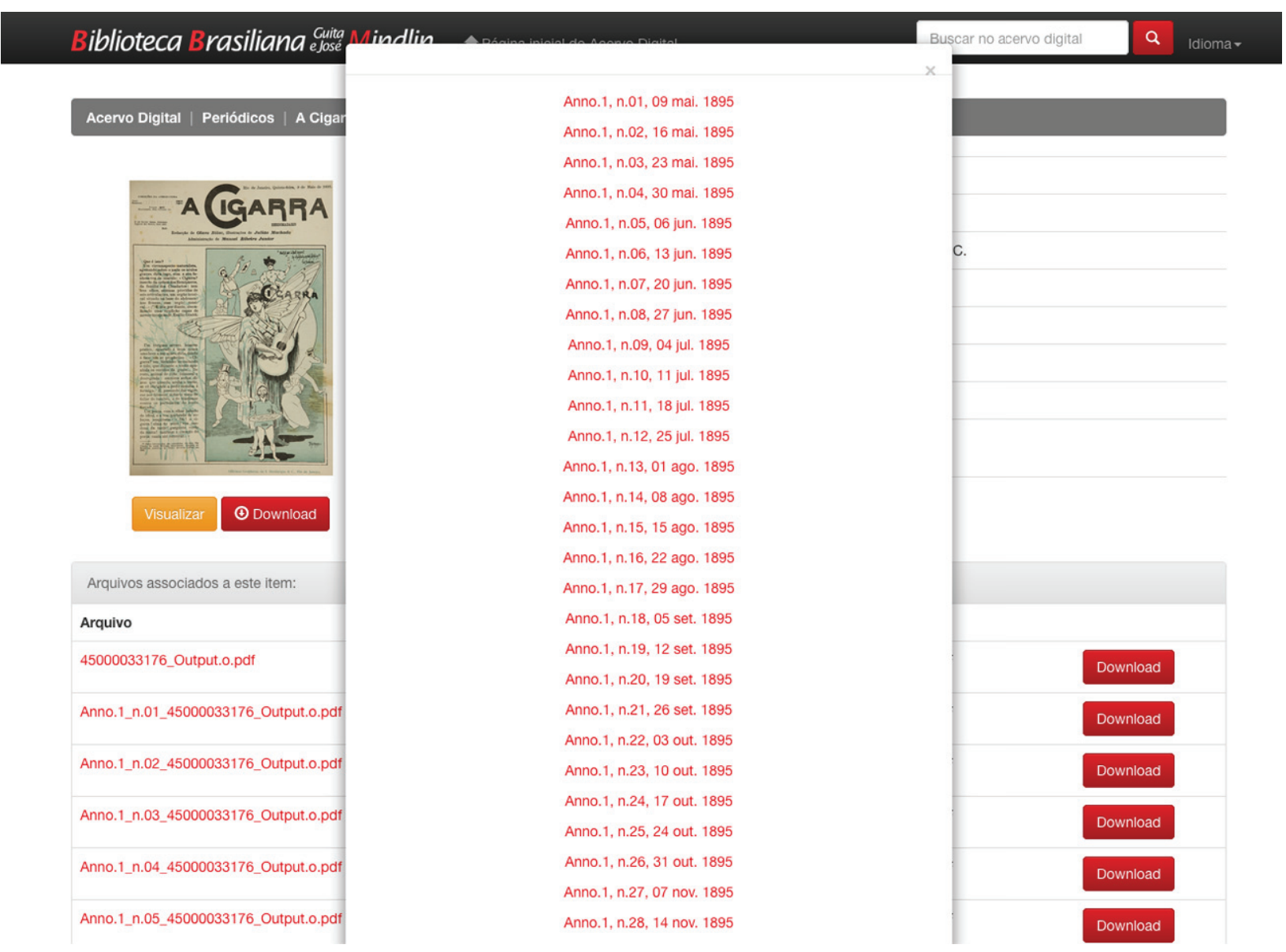

Figura 10 - Exemplo de Obra em fascículos.

Fonte: BBM

Isto foi necessário devido a muitas obras volumadas estarem em uma ou em um conjunto de encadernações. Nestes casos cada encadernação é tratada como um ítem da biblioteca, da mesma forma que o item físico. Além da Visualização é possível também o download da versão em PDF. Nesta é possível a busca no texto completo, devido ao tratamento dado por OCR (optical character recognition - reconhecimento ótico de caracteres. Para o controle e documentação das alterações, foi utilizado o GitLab ${ }^{x \times v}$ da USP.

A nova plataforma foi ao ar em julho de 2017 (KIYOMURA, 2017; LIMA,
2017). Foram 2 anos de desenvolvimento, correções e migração de dados, entre outros ajustes. Atualmente ${ }^{\mathrm{XVI}} 3415$ itens estão disponíveis para consulta e download na nova plataforma da Biblioteca Digital da BBM no endereço: https://digital.bbm. usp.br. E semanalmente novas obras são acrescentadas no acervo digital.

\section{Considerações Finais}

As estratégias para garantir 0 acesso ao patrimônio cultural, sobretudo aos acervos bibliográficos, necessariamente passam por processos de digita- 
lização e desenvolvimento de bibliotecas digitais. Conforme Robert Darnton (2013, p. 10), bibliotecário acadêmico e diretor da Biblioteca da Universidade de Harvard entre 2007 e 2016, diversos tipos de materiais "[...] que estavam restritos à pesquisa local em bibliotecas e museus poderão - em alguns casos, já podem - ser consultados de qualquer lugar, bastando, para isso, acesso à internet". Ou seja, Os acervos digitalizados, quando disponibilizados, tornam-se o principal recurso de acesso a materiais que, de outra maneira, poderiam permanecer desconhecidos do grande público, e podem contribuir para "[...] mudanças importantes para o campo do saber" (DARNTON, 2013, p. 10).

Apesar do atual contexto, uma dedicada equipe técnica assumiu a tarefa de reativar as atividades de digitalização e administração da Biblioteca Digital da BBM, que passou de projeto para processo na BBM, tornando-se insumo para novos projetos, experiências e análises, sobretudo, em Ciência da Informação (na Biblioteconomia em Representação e Organização da Informação, Preservação Digital, Disseminação da Informação etc.) e, como apontam Guerreiro e Borbinha (2014), nas Humanidades Digitais, para a construção de ferramentas de análises, linked data, e apresentações mais imediatas e intuitivas para facilitar a aquisição cognitiva.

Uma grande preocupação da coordenação técnica da Biblioteca Digital da BBM é em relação a preservação digital|XXVII, que, em 2017, organizou o I Seminário BBM de Bibliotecas Digitais: Preservação Digital e AcessoxxVIII. O seminário versou sobre as especificidades, procedimentos e estratégias envolvidas nos processos de digitalização e disponibilização de conteúdos, além do conjunto de atividades e processos que visam garantir o acesso continuado, a longo pra- zo, com qualidade, autenticidade e confiabilidade aos objetos digitais. A ideia foi trazer a discussão sobre a preservação digital (entre outros assuntos correlatos como: metadados e representação descritiva e temática; curadoria digital; conceitos de bibliotecas digitais; projetos e expeciências em outras instituições, etc) para a BBM e sua importância também dentro da instituição, sobretudo para a formalização de políticas de digitalização, de preservação digital e acesso. Tópicos estes em que a BBM já foi bem mais engajada institucionalmente.

Como próximos passos, a equipe técnica está estudando um modo para estabelecer procedimentos de atualização do software DSpace para novas versões, sem impactar em customizações, procedimentos e integridade dos registros bibliográficos. Também está nos planos, desenvolver uma interface de busca integrada que agregue além da Biblioteca Digital, a Base de dados do Arquivo da BBM (em desenvolvimento) e também bases de dados de instituições que vierem a ser parceiras.

Porém, é importante ressaltar que, institucionalmente, a BBM ainda tem um longo percurso. Em qualquer organização, é preciso a definição de uma estrutura geral/organograma mínimo. Embora muitas das atividades desenvolvidas sejam interdependentes e realizadas em conjunto, é necessária a definição das atribuições de cada setor e de cada função, justamente para atribuir as responsabilidades de cada um dentro da organização. Atentar para as normas e regulamentações vigentes é também indispensável.

Além disso, a realização e consolidação de parcerias, sobretudo a manutenção de cooperações técnicas, grupos de trabalho, projetos interdisciplinares de pesquisa, é essencial para 
o desenvolvimento da instituição, assim como, de seus corpo efetivo e daqueles que fazem seu uso para o desenvolvimento da ciência.

Assim, é fundamental que os tomadores de decisão se sensibilizem e se conscientizem sobre a importância destes (e outros) pontos, sobretudo, para a própria sustentabilidade institucional, resgatando os ideais originais de compromisso e engajamento para com a difusão dos acervos de memória e cultura, pois a BBM possui enorme potencial para se consolidar como um centro interdisciplinar de informação e documentação, pesquisa e difusão científica e assim ser, efetivamente, um espaço convergente para as mais diversas áreas do conhecimento.

\section{Referências}

ALENCAR, Anderson F. et al. Plataforma Corisco: os casos da Brasiliana USP e do Instituto Paulo Freire, 2012. Disponível em: http://wsl.softwarelivre.org/2012/0008/52.pdf. Acesso em: 06 dez. 2018.

BRASILIANA USP. Princípios. 2009. Disponível em: https://web.archive.org/web/20090622071548/ http://www.brasiliana.usp.br:80/bd_principios. Acesso em: 10 dez. 2018.

CGI.BR. Memorando de intenções sobre conteúdos digitais. 2007. Disponível em: https://cg-conteudos.cgi.br/memorando-de-intencoes. Acesso em: 10 dez. 2018.

DARNTON, Robert. Memória digital e o futuro da comunicação: entrevista com Robert Darnton. [Entrevista cedida a] STRELOW, Aline. [Tradução] FERRARI, Miriam. Em Questão: Revista da Facul- dade de Biblioteconomia e Comunicação da UFRGS, Porto Alegre, v.19, n.1, p.9-20, jan./jun. 2013.

GUERREIRO, Dália; BORBINHA, José Luís. Humanidades Digitais: novos desafios e oportunidades. Cadernos BAD, n.1, p.63-78, jan./jun. 2014. Disponível em: https://www.bad.pt/publicacoes/ index.php/cadernos/article/view/1060/pdf. Acesso em: 19 dez. 2018.

INTERNATIONAL FEDERATION of LIBRARY ASSOCIATIONS and INSTITUTIONS - IFLA. Diretrizes para planejamento de digitalização de livros raros e coleções especiais. Disponível em: https:// www.ifla.org/files/assets/rare-books-and-manuscripts/rbms-guidelines/guidelines-for-planning-digitization-pt.pdf. Acesso em: 14 dez. 2018.

JANCSÓ, István. Um historiador do Brasil: István Jancsó. [Depoimento cedido a] MOREL, Marco; SLEMIAN, Andréa; LIMA, André Nicacio (orgs.). São Paulo: Hucitec, 2010. 400p.

KIYOMURA, Leila. Os livros raros do acervo da Brasiliana já estão no ar. Entrevistado: Rodrigo Moreira Garcia. Jornal da USP, São Paulo, 2017. Disponível em: http://jornal.usp.br/cultura/os-livros-raros-do-acervo-da-brasiliana-ja-estao-no-ar/. Acesso em: 18 dez. 2018.

LIMA, Juliana Domingos de. 3.000 livros raros da Biblioteca Brasiliana da USP estão disponíveis para download. Entrevistado: Rodrigo Moreira Garcia. Nexo, São Paulo, 2017. Disponível em: https://www.nexojornal.com.br/ expresso/2017/07/20/3.000-livros-raros-da-Biblioteca-Brasiliana-da-USP-estão-disponíveis-para-download. Acesso em: 18 dez. 2018.

MANCEBO, Deise. Crise político-econômica no Brasil: breve análise da educação superior. Educação \& Sociedade, Campinas, v. 38, n. 141, p. 875-892, Dec. 2017. Disponível em: http://dx.doi. org/10.1590/es0101-73302017176927. Acesso em: 11 dez. 2018.

Recebido em 20/12/2018 Aprovado em 24/01/2019 
I Rodrigo Moreira Garcia. Mestre em Ciência da informação pela FFC/UNESP/Marília. Bibliotecário na Biblioteca Brasiliana Guita e José Mindlin. Universidade de São Paulo, Brasil. Contato: garcia.rodrigo@usp.br

II FAPESP. Por uma Biblioteca Brasiliana Digital. 2008. Disponível em: https://bv.fapesp.br/pt/auxilios/5175/ por-uma-biblioteca-brasiliana-digital/. Acesso em: 05 de dez. 2018.

III DSPACE. Disponível em: https://duraspace.org/dspace/. Acesso em: 06 dez.2018.

IV DJATOKA. Disponível em: https://sourceforge.net/ projects/djatoka/. Acesso em: 06 dez. 2018.

V IIPIMAGE. Disponível em: https://github.com/iipimage. Acesso em: 06 dez. 2018.

VI BOOKREADER. Disponível em: https://openlibrary. org/dev/docs/bookreader. Acesso em: 06 dez. 2018.

VII WIKIPÉDIA. Reconhecimento ótico de caracteres. Disponível em: https://pt.wikipedia.org/wiki/Reconhecimento_ótico_de_caracteres. Acesso em: 06 dez. 2018.

VIII DUBLIN CORE. Disponível em: http://dublincore. org. Acesso em: 06 dez. 2018.

IX Até a presente data, a BBM não possui um organograma mínimo formalizado, definindo seus setores e respectivos responsáveis/coordenadores técnicos, conforme pode ser constatado em seu regimento interno: UNIVERSIDADE DE SÃO PAULO. Resolução $n^{\circ} 7167$, de 16 de Fevereiro de 2016. Disponível em: http://www. leginf.usp.br/?resolucao=resolucao-no-7167-de-16-de-fevereiro-de-2016. Acesso em: 07 dez. 2018.

$X$ OPEN ACCESS MAX-PLANCK-GESELLSCHAFT. Berlin Declaration on Open Access to Knowledge in the Sciences and Humanities. Disponível em: https://openaccess.mpg.de/Berlin-Declaration. Acesso em: $10 \mathrm{dez}$. 2018.

XI OPEN ARCHIVES INITIATIVE. Disponível em: http:// www.openarchives.org. Acesso em: 10 dez. 2018.

XII Expressão em geral usada na política quando um governo ou uma situação começa a ficar desorganizada e sem um ponto de referência. $\mathrm{O}$ autor deste artigo tomou conhecimento da expressão em uma cordial troca de e-mails com o prof. ${ }^{\circ}$ Briquet de Lemos.

XIII Duas bibliotecárias realocaram-se para outras unidades. Um bibliotecário de outra unidade, com experiência no desenvolvimento e atuação em Biblioteca Digitais, optou pela BBM. Somente a pouco mais de um ano foi possível, após intermitentes contratações de técnicos conservadores terceirizados, ocupar o laboratório de conservação, também com uma bibliotecária de outra unidade que, sem experiência em conservação, mas com interesse na área, está se capacitando para a função.

XIV DEDALUS. Disponível em: http://dedalus.usp.br. Acesso em: 17 dez. 2018.

$\mathrm{XV} \quad \mathrm{O}$ analista de sistemas com esse perfil se desligou da Universidade no primeiro PIDV.

XVI STI. Disponível em: https://www.sti.usp.br. Acesso em: 17 dez. 2018.

XVII CETI-SC. Disponível em: http://cetisc.sti.usp.br. Acesso em 17 dez. 2018.

XVIII BIBLIOTECA DIGITAL DE TESES E DISSERTAÇÕES DA UNIVERSIDADE DE SÃO PAULO. Disponível em: http://www.teses.usp.br. Acesso em: 17 dez. 2018.

XIX SIBi-USP. Disponível em: http://www.sibi.usp.br. Acesso em: 17 dez. 2018.

XX UNESCO. Communication and Information: CDS/ ISIS database software. Disponível em: http://www. unesco.org/new/en/communication-and-information/ information-society/open-source-and-low-cost-technologies/information-processing-tools/cdsisis-database-software/. Acesso em: 17 dez. 2018.

XXI AACR2. Disponível em: http://www.aacr2.org. Acesso em: 17 dez. 2018.

XXII LIBRARY OF CONGRESS. MARC Standards: Library of Congress - Network Development and MARC standards office. Disponível em: https://www.loc.gov/ marc/. Acesso em: 17 dez. 2018.

XXIII DURASPACE. Disponível em: https://duraspace. org. Acesso em: 06 dez. 2018.

XXIV OPENDOAR. Disponível em: http://v2.sherpa. ac.uk/opendoar/. Acesso em: 18 dez. 2018.

XXV GIT USP. Disponível em: https://git.uspdigital.usp. br/bbm/dspace-bbm2. Acesso em: 18 dez. 2018.

XXVI Dado de Dezembro de 2018.

XXVII Ver: REDE CARINIANA. IBICT. MCTIC. Preservação Digital. Disponível em: http://cariniana.ibict.br/index.php/pre-dig. Acesso em: 18 dez. 2018.

XXVIII I SEMINÁRIO BBM DE BIBLIOTECAS DIGITAIS: Preservação Digital e Acesso. Disponível em: https:// www.youtube.com/playlist?list=PLWE9sM1OP8qyOJC_ ShyshnjAg97HpJyJx. Acesso em: 18 dez. 2018. 